\title{
Toughness Degradation Mechanism for Reheated Mo-Ti-B Bearing Weld Metal
}

\author{
Nobuo TEZUKA, Chiaki SHIGA, Tadamasa YAMAGUCHI, ${ }^{1)}$ Jan BOSANSKY, ${ }^{2)}$ Kouichi YASUDA and \\ Yoshihiro KATAOKA
}

Technical Research Laboratories, Kawasaki Steel Corporation, Kawasaki-cho, Chuo-ku, Chiba, Chiba-ken, 260 Japan. 1) Welding Rod Sales Department, Steel Business Planning \& Sales Division, Kawasaki Steel Corporation, Uchisaiwai-cho, Chiyoda-ku, Tokyo, 100 Japan. $\quad$ 2) Welding Research Institute, Bratislava, Slovakia.

(Received on May 8, 1995; accepted in final form on July 24, 1995)

\begin{abstract}
The variations of toughness of reheated weld metals were studied in the Pcm range of 0.13 to 0.20 mass $\%$, using welding thermal cycle simulator. The reheating temperature dependence of toughness is quite different between weld metal of low $\mathrm{Pcm}$ and that of high $\mathrm{Pcm}$. There is more remarkable toughness degradation in the range of 900 to $1000^{\circ} \mathrm{C}$ than that of 1200 to $1350^{\circ} \mathrm{C}$ in rehaating of weld metals with high $\mathrm{Pcm}$. The toughness degradation in 900 to $1000^{\circ} \mathrm{C}$ is characterized by Ti-B bearing weld metal with high Pcm. The toughness degradation of high $\mathrm{Pcm}$ weld metal in 1200 to $1350^{\circ} \mathrm{C}$ is not more remarkable than that of low Pcm such as Si-Mn weld metal. By increasing the $\mathrm{Pcm}$, the toughness degradation in 900 to $1000^{\circ} \mathrm{C}$ is more intensified, and that in 1200 to $1350^{\circ} \mathrm{C}$ is more recovered. The following quantitative evaluation on the toughness degradation is conducted by microstructural analysis using Petch's relationship. The toughness degradation in reheating at $1000^{\circ} \mathrm{C}$ which is corresponding to be $72^{\circ} \mathrm{C}$ in Charpy impact transition temperature comes from the component of grain coarsening, about $46^{\circ} \mathrm{C}$, and that of MA constituents, about $26^{\circ} \mathrm{C}$. On the other hand, the toughness degradation in reheating at $1350^{\circ} \mathrm{C}, 32^{\circ} \mathrm{C}$ in Charpy impact transition temperature comes from the component of grain coarsening, about $11^{\circ} \mathrm{C}$, and that of $\mathrm{MA}$ constituents, about $21^{\circ} \mathrm{C}$.
\end{abstract}

KEY WORDS: welding; thermal cycle; weld metal; heat affected zone; toughness; microstructure; phase transformation; grain size.

\section{Introduction}

The low temperature toughness has been required for the offshore structure such as jackets, mobile drilling units and line pipe used in the north sea or in the arctic region. In order to meet such a stringent requirement, $\mathrm{Ti}-\mathrm{B}$ bearing weld metal has been used because it forms acicular ferrite. ${ }^{1-6)}$ The fraction of acicular ferrite which depends on the Pcm varies with the oxygen content of weld metal. ${ }^{7)}$ A good combination of Pcm and oxygen content in weld metals is greatly important for the improvement of toughness through the microstructural refinement.

Practical analysis of many Charpy impact test results on the Ti-B bearing weld metals has given us the information on a scattering of Charpy values, which appears to be due to local brittle zone that exists in reheated zones resulting from multipass welding. However, there are only a few papers which report the effect of reheating cycles on the toughness of weld metals.

This paper reports an investigation on the effects of welding thermal cycles on the notch toughness of Ti-B bearing weld metals; to examine the toughness of reheated weld metals resulting from multipass welding. We have much focus on the clarification of the mechanism of toughness degradation in reheated weld metals.

\section{Experimental Procedure}

\subsection{Materials and Welding}

The ten kinds of single pass submerged arc weld metals in bead-in-groove of X-65 grade line-pipe steels were prepared, using $\mathrm{SiO}_{2}-\mathrm{CaO}-\mathrm{CaF}_{2}$ system fused fluxes and several welding wires to make the combination of alloy elements among $\mathrm{Si}, \mathrm{Mn}, \mathrm{Mo}, \mathrm{Ti}$ and $\mathrm{B}$. The welds were produced in heat input of $7.1 \mathrm{~kJ} / \mathrm{mm}$. The chemical compositions of weld metals obtained are given in Table 1. The Pcm values of the weld metals were designed and varied in the range of between 0.13 and 0.20 mass $\%$, mainly with changing the contents of manganese and molybdenum. Although the carbon equivalents were originally developed to evaluate the cold cracking susceptibility of base metal, these equations are also useful to expect the microstructure of weld metal. In the paper, we adopted $\mathrm{Pcm}$ as a parameter of weld metal contents, because $\mathrm{Pcm}$ equation involves major elements in the weld metal in comparison with other carbon equivalent equations. 
Table 1. Chemical compositions of weld metals. (mass\%)

\begin{tabular}{cccccccccccccccccccc} 
Mark & $\mathrm{C}$ & $\mathrm{Si}$ & $\mathrm{Mn}$ & $\mathrm{Al}$ & $\mathrm{Ti}$ & $\mathrm{Cu}$ & $\mathrm{Ni}$ & $\mathrm{Cr}$ & $\mathrm{Mo}$ & $\mathrm{V}$ & $\mathrm{Nb}$ & $\mathrm{B}$ & $\mathrm{N}$ & $\mathrm{O}$ & $\mathrm{Pcm}$ & \\
\hline A & 0.066 & 0.31 & 1.57 & 0.012 & 0.021 & 0.18 & 0.09 & 0.05 & 0.199 & 0.041 & 0.017 & 0.0012 & 0.0042 & 0.0266 & 0.191 \\
B & 0.064 & 0.37 & 1.40 & 0.012 & 0.025 & 0.19 & 0.09 & 0.04 & 0.200 & 0.039 & 0.018 & 0.0014 & 0.0040 & 0.0357 & 0.184 \\
C & 0.046 & 0.38 & 1.65 & 0.017 & 0.030 & 0.08 & 0.10 & 0.04 & 0.294 & 0.030 & 0.022 & 0.0006 & 0.0039 & 0.0256 & 0.174 \\
D & 0.052 & 0.43 & 1.50 & 0.016 & 0.029 & 0.08 & 0.10 & 0.04 & 0.300 & 0.030 & 0.022 & 0.0005 & 0.0039 & 0.0342 & 0.193 \\
E & 0.059 & 0.33 & 1.61 & 0.011 & 0.023 & 0.05 & 0.01 & 0.03 & 0.179 & 0.039 & 0.017 & 0.0016 & 0.0031 & 0.0210 & 0.179 \\
F & 0.046 & 0.31 & 1.37 & 0.015 & 0.027 & 0.17 & 0.14 & 0.04 & 0.175 & 0.025 & 0.023 & 0.0020 & 0.0066 & 0.0249 & 0.162 \\
G & 0.048 & 0.31 & 1.31 & 0.014 & 0.022 & 0.14 & 0.14 & 0.03 & 0.104 & 0.024 & 0.022 & 0.0012 & 0.0050 & 0.0226 & 0.150 \\
H & 0.043 & 0.26 & 1.35 & 0.013 & 0.014 & 0.13 & 0.14 & 0.03 & 0.056 & 0.024 & 0.023 & 0.0009 & 0.0035 & 0.0261 & 0.140 \\
I & 0.045 & 0.27 & 1.26 & 0.008 & 0.011 & 0.13 & 0.14 & 0.03 & 0.093 & 0.024 & 0.018 & 0.0007 & 0.0035 & 0.0372 & 0.139 \\
J & 0.035 & 0.28 & 1.32 & 0.012 & 0.014 & 0.17 & 0.15 & 0.02 & 0.004 & 0.025 & 0.020 & 0.0009 & 0.0033 & 0.0221 & 0.130
\end{tabular}

$\mathrm{Pcm}=\mathrm{C}+\mathrm{Si} / 30+(\mathrm{Mn}+\mathrm{Cu}+\mathrm{Cr}) / 20+\mathrm{Ni} / 60+\mathrm{Mo} / 15+\mathrm{V} / 10+5 \mathrm{~B}$

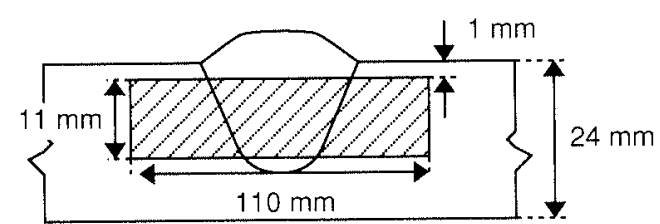

Fig. 1. Schematic illustration showing the position of weld metals in bead-in-groove and thermal cycle specimen.

\subsection{Thermal Cycle and Charpy Impact Tests}

Welding simulator, Thermorestor equipment was used to simulate the reheated weld metals. The specimens supplied for the thermal cycle were obtained from single-pass welds as shown in Fig. 1. The thermal cycle with various maximum temperatures between 600 and $1350^{\circ} \mathrm{C}$ which don't have holding time were given to simulate welding thermal cycles; the cooling pattern corresponding to that of welding with a heat input of $5 \mathrm{~kJ} / \mathrm{mm}$ (cooling time of $40 \mathrm{sec}$ from 800 to $500^{\circ} \mathrm{C}$ ). Full-sized Charpy specimens were then machined from the thermal cycled specimens, to perform an impact test at $-60^{\circ} \mathrm{C}$. A notch was located on the weld centerline.

\subsection{Analysis of Microstructure}

The microstructures of both as-welded metal and reheated weld metals were observed with optical microscopy and transmission electron microscopy (TEM) because carbon extraction replica method with TEM was useful for the observation of fine-grained microstructures. The samples used for TEM observation were deeply etched with a $3 \%$ nital solution. Carbon film was then evaporated on the surface of the sample to observe grain boundary clearly. The average grain size and the area fraction of MA constituent were evaluated by point counting method.

\section{Results}

\subsection{Notch Toughness of Weld Metals}

Figure 2 shows the effect of maximum temperatures on Charpy impact transition temperature, vTrs, for high Pcm weld metals with medium and high oxygen levels characterized by Mo-Ti-B compositions. A remarkable degradation of notch toughness can be seen at the maximum temperature of $1000^{\circ} \mathrm{C}$. The differences of the transition temperature between as-welded and $1000^{\circ} \mathrm{C}$ reheating conditions are 72 and $55^{\circ} \mathrm{C}$ for medium and

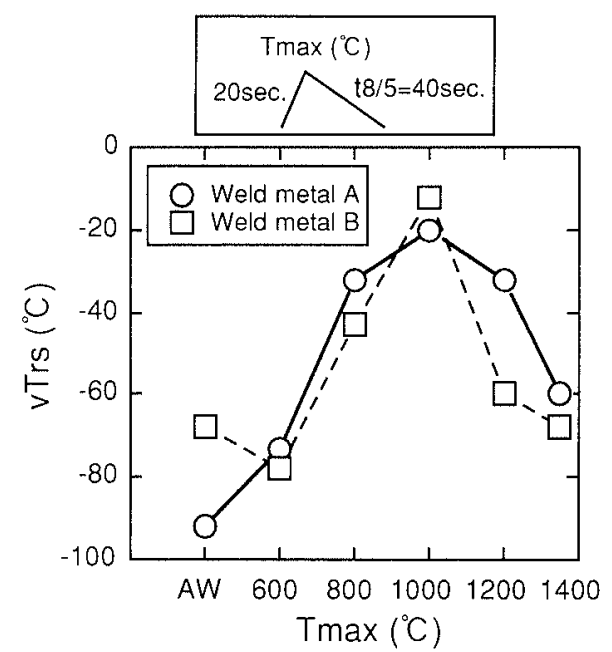

Fig. 2. Effect of maximum temperature on transition temperature of high Pcm (Mo-Ti-B bearing) weld metals. (Weld metal A: $\mathrm{Pcm}=0.191$ mass $\%, O=0.0266$ mass $\%$, Weld metal B: $\mathrm{Pcm}=0.184$ mass $\%, \underline{O}=0.0357$ mass $\%$ )

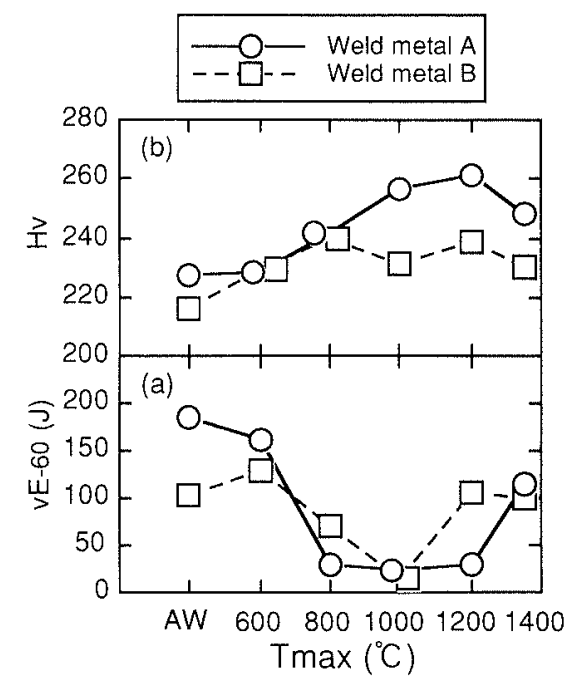

Fig. 3. Effect of maximum temperature on (a) toughness and (b) hardness of high Pcm (Mo-Ti-B bearing) weld metals. (Weld metal A: Pcm $=0.191$ mass $\%, \underline{O}=$ 0.0266 mass $\%$, Weld metal $B: P c m=0.184$ mass $\%$, $\mathrm{O}=0.0357$ mass $\%$ )

high oxygen levels, respectively. Figure 3(a) shows the effect of maximum reheating temperature on the absorbed energy at $-60^{\circ} \mathrm{C}$ of weld metals with medium 


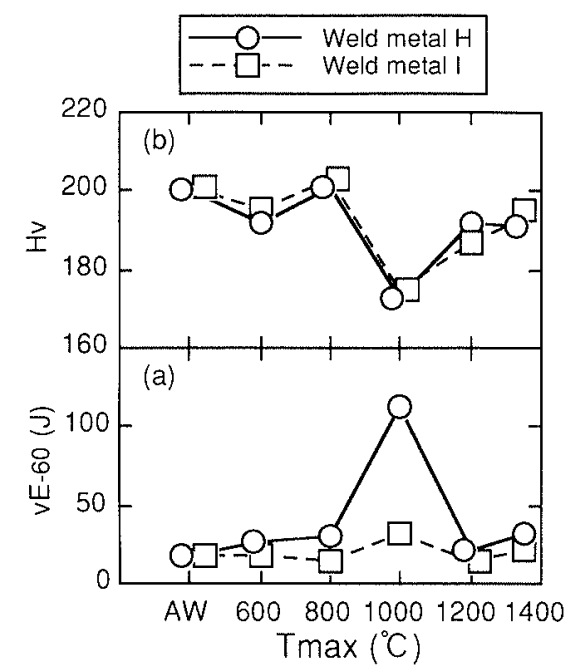

Fig. 4. Effect of maximum temperature on (a) toughness and (b) hardness of low Pcm weld metals. (Weld metal $\mathrm{H}$ : $\mathrm{Pcm}=0.140$ mass $\%, \mathrm{O}=0.0261$ mass $\%$, Weld metal $\mathrm{I}$ : $\mathrm{Pcm}=0.139$ mass $\%, \underline{\underline{O}}=0.0372$ mass $\%$ )

and high oxygen contents. Reheating up to $600^{\circ} \mathrm{C}$ provided good notch toughness above $100 \mathrm{~J}$ at $-60^{\circ} \mathrm{C}$, which was almost the same with that of as-welded one. But the reheating from 800 to $1000^{\circ} \mathrm{C}$ demonstrated the degradation behavior of notch toughness with the bottom of $1000^{\circ} \mathrm{C}$, which is corresponding to the fine austenite grain region. Furthermore the reheating over $1200^{\circ} \mathrm{C}$ began to recover the toughness and the reheating to $1350^{\circ} \mathrm{C}$ recovered remarkably in comparison with that of $1000^{\circ} \mathrm{C}$. The oxygen content has little influence on the toughness of other specimens than as-welded, 800 and $1200^{\circ} \mathrm{C}$ ones. The notch toughness of weld metals reheated to 800 and $1200^{\circ} \mathrm{C}$ depended on the oxygen content; that is, higher oxygen content led to better notch toughness. The hardness of weld metals reheated to between 800 and $1200^{\circ} \mathrm{C}$ tended to increase in comparison with that of as-welded metals as shown in Fig. 3(b).

Similarly, Fig. 4(a) shows the effects of maximum reheating temperature on the notch toughness of low Pcm weld metals with medium and high oxygen levels characterized by $\mathrm{Si}-\mathrm{Mn}$ compositions. In the case of low $\mathrm{Pcm}$ weld metals, the maximum temperature of reheating to $1000^{\circ} \mathrm{C}$ improved the notch toughness, while other reheating kept the poor notch toughness which is almost the same with that of as-welded one. The hardness at reheating of $1000^{\circ} \mathrm{C}$ demonstrated the softening behavior which was quite different from that of high $\mathrm{Pcm}$ weld metal as shown in Fig. 4(b).

The each relationship between notch toughness and Pcm of weld metals obtained for as-welded, reheating at 1000 and $1350^{\circ} \mathrm{C}$ conditions is shown in Figs. 5(a), 5(b) and 5(c). The notch toughness increased with $\mathrm{Pcm}$ in as-welded and $1350^{\circ} \mathrm{C}$ reheating conditions, while it decreased with the increase of $\mathrm{Pcm}$ in the case of reheating at $1000^{\circ} \mathrm{C}$. In either case, high oxygen content $(0.0342-$ $0.0372 \mathrm{mass} \%$ ) led to poorer notch toughness than medium and low oxygen contents. On the other hand, hardness of weld metals of both as-welded and reheating at $1000^{\circ} \mathrm{C}$ increased with $\mathrm{Pcm}$, that is, hardness behavior

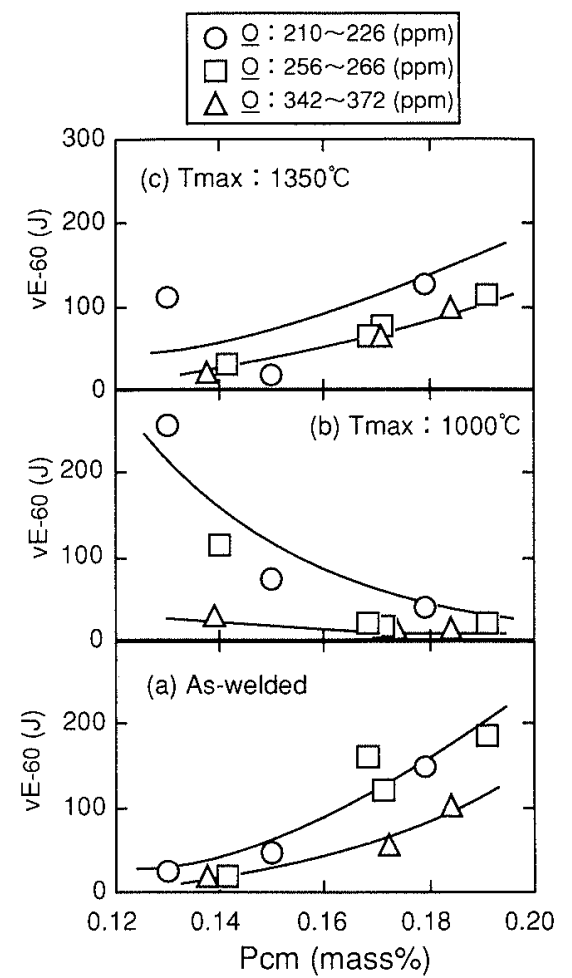

Fig. 5. Relation between toughness and carbon equivalent (Pcm) of weld metals in (a) as-welded and (b) $1000^{\circ} \mathrm{C}$ and (c) $1350^{\circ} \mathrm{C}$ reheating conditions.

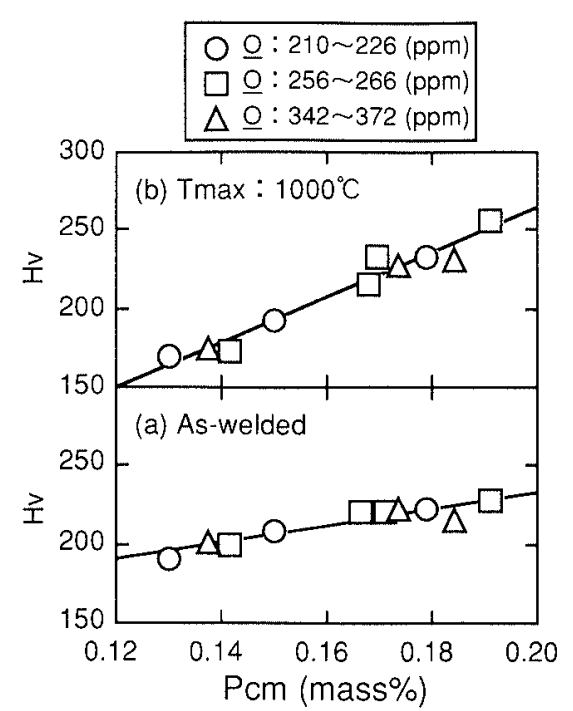

Fig. 6. Relation between hardness and Pcm of weld metals in (a) as-welded and (b) $1000^{\circ} \mathrm{C}$ reheating conditions.

is independent of oxygen content, as shown in Figs. 6(a) and $\mathbf{6}(\mathbf{b})$.

\subsection{Microstructure Observation of Weld Metals}

Figure 7 shows the effect of reheating on the optical $(\times 400)$ and TEM $(\times 3000)$ microstructures of weld metals with high $\mathrm{Pcm}(0.191$ mass \%: weld metal A). The optical microstructures, as a whole, seem to be so fine, regardless of different thermal cycles, but the difference of the microstructures can be clearly distinguished through TEM observation. The microstructure of a large volume fraction of fine acicular ferrite with small amount of MA constituent was formed in as-welded metal. In 


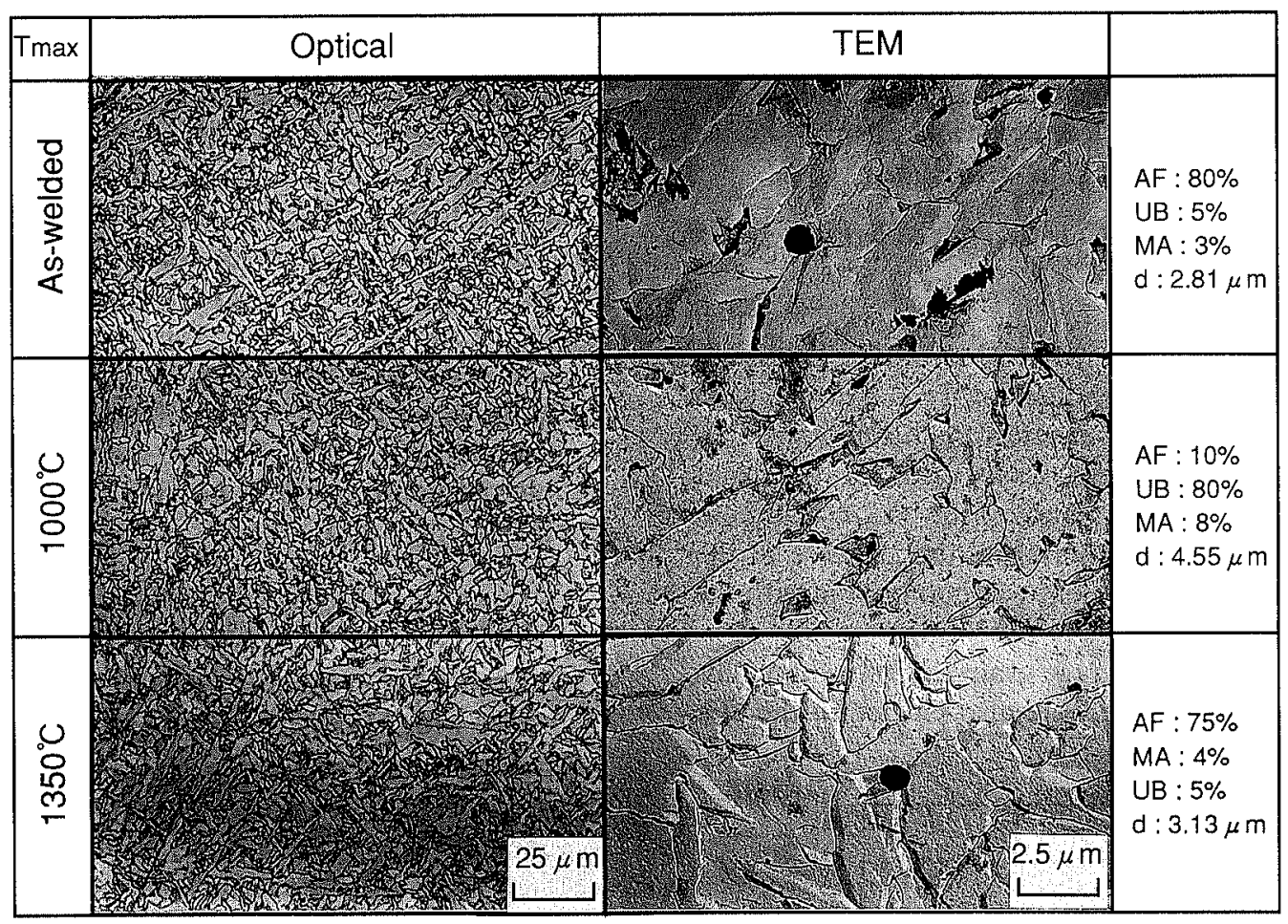

Fig. 7. Change in optical and TEM microstructures of high Pcm weld metal through reheating. $(\mathrm{A}: \mathrm{Pcm}=0.191$ mass $\%, \underline{O}=0.0266$ mass $\%$ )

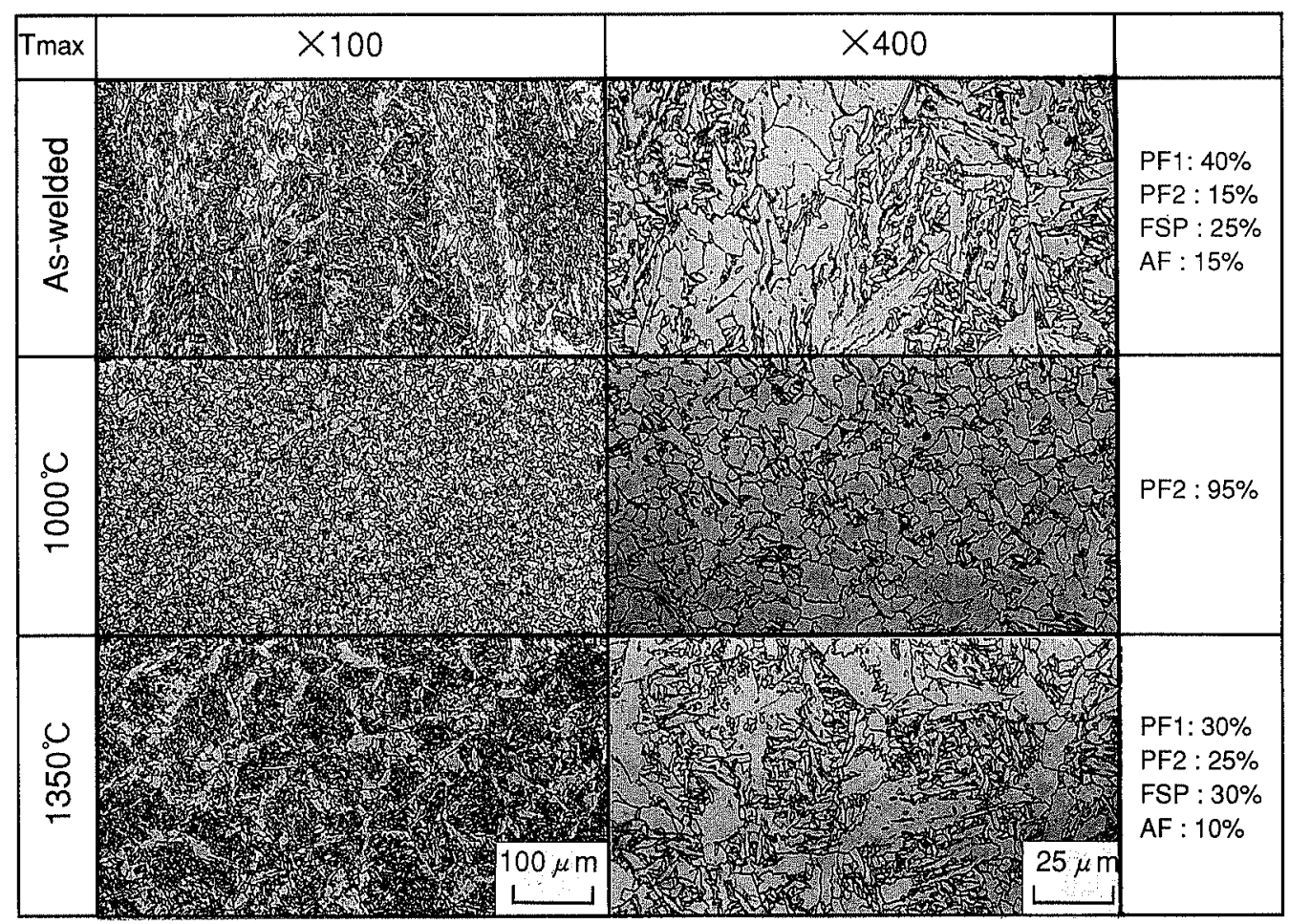

Fig. 8. Change in optical microstructures of low Pcm weld metal through reheating. ( $\mathrm{H}: \mathrm{Pcm}=0.140$ mass $\%$, $\mathrm{O}=0.0261$ mass $\%$ )

the weld metal reheated to $1350^{\circ} \mathrm{C}$, acicular ferrite was also observed, but it was a little coarser than that of as-welded metal. However, upper bainite with larger amount of aligned MA particles, instead of acicular ferrite, was dominant in the one reheated at $1000^{\circ} \mathrm{C}$.

The effect of reheating on the optical microstructures $(\times 100$ and $\times 400)$ of weld metals with low Pcm $(0.140$ mass $\%)$ and medium oxygen content $(0.0261$ mass $\%)$ is shown in Fig. 8. Large amount of heterogeneous polygonal ferrite (PF1) was formed in as-welded metal and this type of microstructure was almost invariable in weld metals reheated up to $800^{\circ} \mathrm{C}$. The coarse polygonal ferrite, which was again observed in the weld metal reheated at $1350^{\circ} \mathrm{C}$, was found to be small in the volume 
fraction. Reheating at $1000^{\circ} \mathrm{C}$ brought about the microstructure relatively fine polygonal ferrite (PF2) which was overall homogeneous. Above mentioned microstructure variation in low Pcm weld metal is similar to that of conventional HAZ in steel plates.

\subsection{Area Fraction of MA Constituent and Average Grain Size}

Figures 9(a) and 9(b) show the variations of notch toughness and the area fraction of MA constituent with maximum temperature obtained for Ti-B bearing weld metals in as welded and as reheated conditions. The area fraction of MA constituent was evaluated by point counting method. The area fraction of MA constituent varied from 3 to $8 \%$. Furthermore, the increase of the area fraction of MA constituent was compatible with the decrease of notch toughness in reheating.

The variations of the average grain size of weld metals with reheating temperature were also plotted in the Fig.

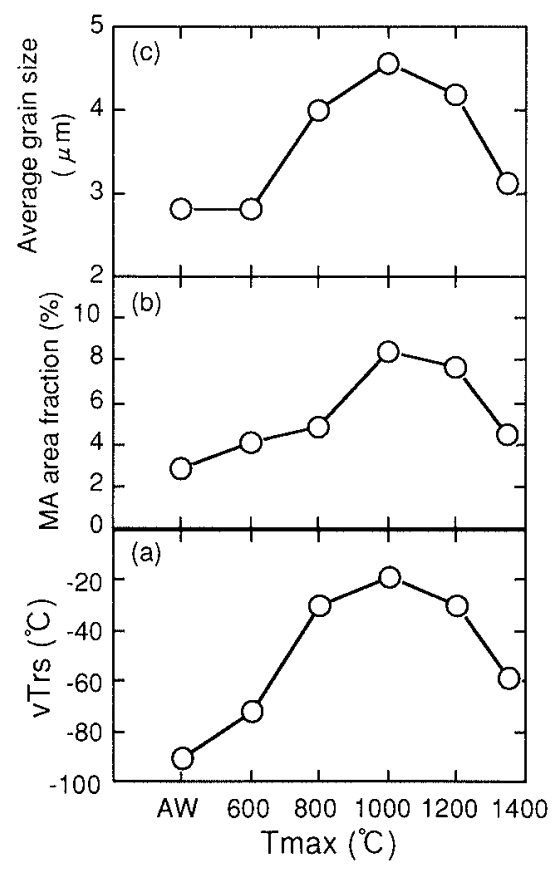

Fig. 9. Relation between maximum temperature and (a) toughness, (b) area fraction of MA and (c) average grain size. (A: $\mathrm{Pcm}=0.191$ mass \%)

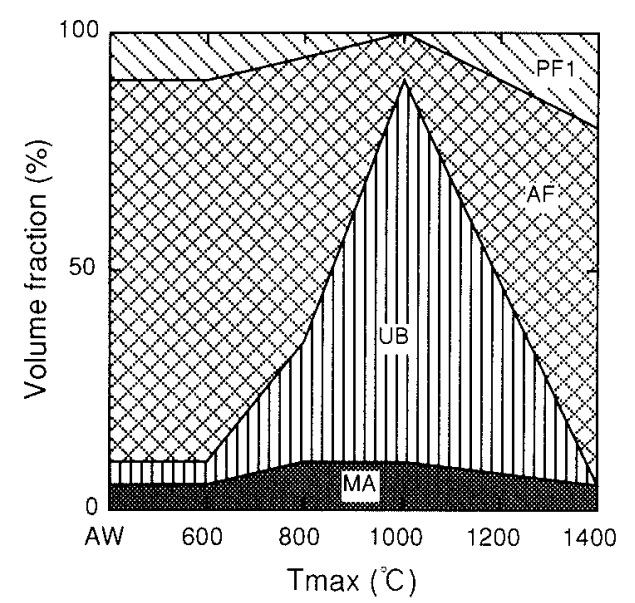

Fig. 10. Relation between maximum temperature and microstructural constituents. (A: $\mathrm{Pcm}=0.191$ mass\%) 9(c). In as-welded metals bearing $\mathrm{Ti}, \mathrm{B}$ and medium oxygen, the average grain size was so fine, approximately $3 \mu \mathrm{m}$, and this refinement is due to high volume fraction of acicular ferrite, about $80 \%$, which consequently resulted in good notch toughness. In reheating at $1000^{\circ} \mathrm{C}$ in fine grained austenite region, the average grain size was coarser than that of as-welded condition, because the acicular ferrite changed into upper bainite. In reheating at $1350^{\circ} \mathrm{C}$ in coarse grained austenite region, the average grain size came close to that of as-welded due to the increase of the volume fraction of acicular ferrite, about $75 \%$. The effect of maximum temperature on microstructure in Ti-B bearing weld metal is shown in Fig. 10.

\section{Discussion}

\subsection{Evaluation of Charpy Impact Transition Tempera- ture with Microstructure Analysis}

Above results demonstrate that the toughness of weld metals bearing Ti-B with high fraction of acicular ferrite is generally deteriorated by reheating in subsequent welding pass with maximum temperature of 600 to $1350^{\circ} \mathrm{C}$; especially there is remarkable toughness degradation in the range of 900 to $1000^{\circ} \mathrm{C}$ which is corresponding to the fine-grained austenite region rather than in the range of 1200 to $1350^{\circ} \mathrm{C}$ which is corresponding to the coarse-grained austenite region. The toughness degradation of 900 to $1000^{\circ} \mathrm{C}$ is characterized by weld metals with high fraction of acicular ferrite in as welded condition and it is not found in weld metals of conventional $\mathrm{Si}-\mathrm{Mn}$ steel with low $\mathrm{Pcm}$ which have low fraction of acicular ferrite.

It should be also noted that the reheating in the range of 1200 to $1350^{\circ} \mathrm{C}$ improves the toughness of weld metals with high fraction of acicular ferrite while it deteriorates that of weld metals with low fraction of acicular ferrite.

The mechanism of toughness degradation through reheating with subsequent welding pass will be discussed below. A coarsening of grain size, increase in MA constituents and precipitations of $\mathrm{Nb}, \mathrm{V}$, etc. should be taken into consideration as metallurgical factors of toughness degradation through reheating. Authors believe that coarsening of grain size from about 3 to $5 \mu \mathrm{m}$ is the factor for the degradation as shown in Fig. 9(a). One of the authors ${ }^{8)}$ illustrated good Petch's relationship between Charpy impact transition temperature, vTrs, and average grain size with second phase of pearlite and bainite in the range of average grain size from 15 to $45 \mu \mathrm{m}$ for HSLA steels produced by normalizing and TMCP and gave the following equation:

$$
v \operatorname{Trs}=56.3-11.4 d^{-1 / 2}
$$

Indeed oxygen contents of weld metals are ten times in comparison with that of HSLA steel plates, but it is assumed that oxygen doesn't affect crack propagation while it does crack initiation. Accordingly, by extrapolating of Eq. (1) to average grain size of about $3 \mu \mathrm{m}$, the variation of $v$ Trs due to the change in the grain size from about 5 to $3 \mu \mathrm{m}$ caused by rehating can be evaluated. The difference in transition temperature, $\Delta v T r s$, between 


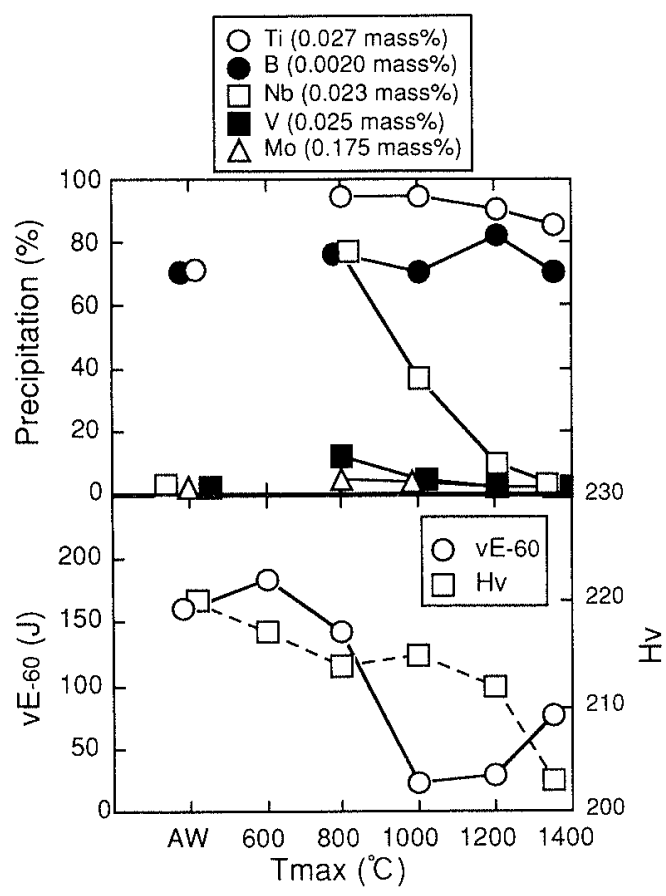

Fig. 11. Variation of (a) toughness and hardness and (b) precipitation with maximum temperature. (F: $\mathrm{Pcm}=$ 0.162 mass $\%$ )

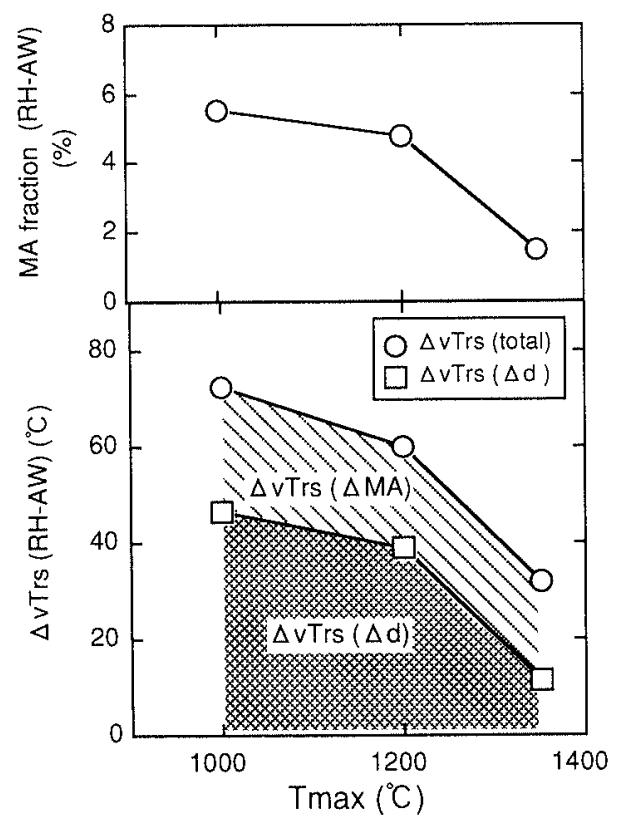

Fig. 12. Difference in (a) transition temperature ( $O$ : total, $\square$ : calculated by the difference of average grain size) and (b) area fraction of MA between as-welded and reheated conditions. (A: $\mathrm{Pcm}=0.191$ mass \%)

as-welded (AW) and each reheating condition (RH) can be given by the following equation:

$$
\Delta \mathrm{vTrs}=\mathrm{v} \operatorname{Trs}(\mathrm{RH})-\mathrm{v} \operatorname{Trs}(\mathrm{AW})=-11.4 \Delta d^{-1 / 2}
$$

where $\Delta d$ is the difference of average grain size between as-welded and reheating conditions.

The amount of precipitations of $\mathrm{Nb}, \mathrm{V}, \mathrm{Mo}, \mathrm{Ti}$ and B were observed using chemical analysis after electrolytically extracting from weld metal reheated at each temperature in solution method. The largest amount of precipitations are observed in the case of reheating at $800^{\circ} \mathrm{C}$ which it is not consistent with the toughness degradation behavior as shown in Fig. 11. We consider that the change in the amount of precipitations has little influence on toughness degradation in reheating.

Figure 12 shows the toughness degradation, $\Delta v T r s$, which is divided between the degradation from the change in average grain size, $\Delta v \operatorname{Trs}(\Delta d)$, and that from MA constituents, $\Delta v \operatorname{Trs}(\Delta M A)$, by using Eq. (2). The degradation from MA constituent was obtained by subtracting $\Delta v \operatorname{Trs}(\Delta d)$ from $\Delta v \operatorname{Trs}$. The component of MA constituent to toughness degradation is at most about $-25^{\circ} \mathrm{C}$. The toughness of weld metal reheated at $1000^{\circ} \mathrm{C}$ was improved from -20 to $-40^{\circ} \mathrm{C}$ in vTrs after tempering at $600^{\circ} \mathrm{C}$ for $45 \mathrm{~min}$. Y. Horii et al.$^{9)}$ report that toughness is improved only by $-20^{\circ} \mathrm{C}$ in vTrs after tempering the reheated weld metal with acicular ferrite including MA constituents.

The component of toughness degradation, $\Delta v \operatorname{Trs}$ ( $\triangle \mathrm{MA}$ ), of $-25^{\circ} \mathrm{C}$ due to MA constituent is almost the same with the improvement of toughness after tempering the reheated weld metal with acicular ferrite including MA constituent, thus it can be said that the evaluation of component of toughness degradation due to coarsening of average grain size is reasonable.

Based on the above analysis, toughness degradation can be interpreted to result mainly from the coarsening of average grain size which depends on the volume fraction of acicular ferrite, while MA constituent is rather second factor for the toughness degradation.

\subsection{Formation Mechanism of Acicular Ferrite}

Microstructure analysis makes it clear that the volume fraction of acicular ferrite determines the average grain size of reheated weld metals. In other works, the reproduction of acicular ferrite in reheating depends on the $\mathrm{Pcm}$ and reheating temperature, that is, higher $\mathrm{Pcm}$ and higher reheating temperature easily reproduce acicular ferrite. In weld metal of high $\mathrm{Pcm}$, the volume fraction of acicular ferrite is only $10 \%$ in reheating at $1000^{\circ} \mathrm{C}$ and is increased up to about $75 \%$ in reheating at $1350^{\circ} \mathrm{C}$. In weld metal of low Pcm, volume fraction of acicular ferrite is below $10 \%$ in reheating at 1000 or $1350^{\circ} \mathrm{C}$.

The volume fraction of acicular ferrite can be well understood when the reproduction of acicular ferrite depends on the three main factors of the $\mathrm{Pcm}$, austenite grain size and supercooling from maximum reheating temperature to nucleation temperature of acicular ferrite.

The formation mechanism of acicular ferrite is the same shear transformation mechanism with that of bainite. ${ }^{10)}$ Accordingly the increase in chemical composition, namely higher $\mathrm{Pcm}$, is effective for the formation of acicular ferrite. Actually Fleck et al. ${ }^{11)}$ report that the increase of Pcm from 0.18 to $0.21 \%$ raises the volume fraction of acicular ferrite from 26 to $85 \%$.

Polygonal ferrite and side plate ferrite are easily formed in the austenite grain boundary, and as a result coarsening of austenite grain increases the volume fraction of acicular ferrite through the reduction of polygonal ferrite because grain coarsening means the decrease in grain 
boundary. Actually Lee ${ }^{12)}$ reports that an intragranular nucleation for acicular ferrite requires moderately large grained prior austenite of 60 to $100 \mu \mathrm{m}$. A large supercooling is suitable for the formation of fine acicular ferrite not only because of the increase in acicular ferrite nucleation sites but also because of the promotion of shear transformation. Christensen et al. ${ }^{13)}$ report that the volume fraction of acicular ferrite increases with the supercooling.

It is clear from the view points of the length of grain boundary and supercooling that reheating at $1000^{\circ} \mathrm{C}$ decreases the volume fraction of acicular ferrite more than that at $1350^{\circ} \mathrm{C}$. Some results on the effect of high heat input on reheated weld metal make it clear that high heat input deteriorates the toughness of weld metal reheated at $1350^{\circ} \mathrm{C}$ in comparison with that of low heat input. The adverse effect of high heat input on the toughness of weld metal reheated at $1350^{\circ} \mathrm{C}$ is reported by Horii et al. ${ }^{9)}$ The adverse effect of high heat input can be explained by the following interpretation; high heat input brings slow cooling rate which results in weakening the shear transformation required for the formation of acicular ferrite.

\section{Conclusion}

The weld metals with Pcm of 0.13 to 0.20 mass $\%$ made in SA welding were given synthetic thermal cycle with the maximum temperature of 600 to $1350^{\circ} \mathrm{C}$ to simulate the reheated zone mainly in two-pass welding.

It was found that reheating temperature dependence of toughness is quite different between weld metal of low Pcm and that of high Pcm.

The conclusions obtained are as follows;

(1) There is more remarkable toughness degradation in the range of 900 to $1000^{\circ} \mathrm{C}$ than that of 1200 to $1350^{\circ} \mathrm{C}$ in reheating of weld metals with high $\mathrm{Pcm}$. The toughness degradation in 900 to $1000^{\circ} \mathrm{C}$ is characterized by Ti-B bearing weld metal with high $\mathrm{Pcm}$. The toughness degradation of high Pcm weld metal in 1200 to $1350^{\circ} \mathrm{C}$ is not more remarkable than that of low Pcm such as $\mathrm{Si}-\mathrm{Mn}$ weld metal.

(2) By increasing the $\mathrm{Pcm}$, the toughness degradation in 900 to $1000^{\circ} \mathrm{C}$ is more intensified, and that in 1200 to $1350^{\circ} \mathrm{C}$ is more recovered.

(3) The toughness degradation in reheating between 800 and $1350^{\circ} \mathrm{C}$ can be explained by the variations of the volume fraction of acicular ferrite and MA con- stituents.

(4) Microstructural analysis using Petch's relationship conducts the following quantitative evaluation on the toughness degradation. The toughness degradation in reheating at $1000^{\circ} \mathrm{C}$ which is corresponding to be $72^{\circ} \mathrm{C}$ in Charpy impact transition temperature comes from the component of grain coarsening, about $46^{\circ} \mathrm{C}$, and that of MA constituents, about $26^{\circ} \mathrm{C}$. On the other hand, the toughness degradation in reheating at $1350^{\circ} \mathrm{C}, 32^{\circ} \mathrm{C}$ in Charpy impact transition temperature comes from the component of grain coarsening, about $11^{\circ} \mathrm{C}$, and that of MA constituents, about $21^{\circ} \mathrm{C}$.

(5) Grain coarsening in (4) represents the increase in average grain size due to the reduction of the volume fraction of acicular ferrite. The volume fractions of acicular ferrite, $80 \%$ in as-welded, $10 \%$ in reheating at $1000^{\circ} \mathrm{C}$ and $75 \%$ in reheating at $1350^{\circ} \mathrm{C}$ correspond to the average grain size of $2.8,4.6$ and $3.1 \mu \mathrm{m}$, respectively.

(6) The volume fraction of acicular ferrite is varied with reheating temperature, which can be systematically explained by using the concept of the shear transformation theory on acicular ferrite formation which depends on supercooling, polygonal ferrite formation in grain boundary and $\mathrm{Pcm}$ in addition to high oxygen content.

\section{REFERENCES}

1) K. Shinmyo, S. Saito, N. Mori, T. Takami and R. Kono: IIW Doc. XII-A 138-77, IX-1073-78, July, (1978).

2) N. Mori, H. Homma, S. Okita and K. Asano: IIW Doc. IX-1158-80, XII-E-7I-80, April, (1980).

3) Y. Horii, S. Okita, M. Wakabayashi and M. Namura: Adv. Weld. Sci. Technol., (1986), 413.

4) T. W. Lau, M. M. Sadowski, T. H. North and G. C. Weatherly: Mater. Sci. Technol, 4 (1988), 52.

5) M. L. E. Davis, R. J. Pargeter and N. Bailey: Met. Constr., (1983), 338.

6) M. Nakanishi and Y. Komizo: Sumitomo Search, (1983), No. 28, Oct., 53.

7) N. N. Potapov: Weld. J., Aug., (1993), 367s.

8) C. Shiga: Benefits of TMCP and Its Applications to HSLA Steels, The 9th Symp. on Metallography, Kosice, Slovakia, April, (1995).

9) Y. Horii, S. Ohkita and M. Wakabayasi: Improvement of Weld Metal Toughness at Reheated Region, The First Pacific Asia Offshore Mechanics Symposium, Seoul, Korea, June, (1990), 103.

10) A. A. B. Sugden and H. K. D. H. Bhadeshia: Metall. Trans. A, 20A (1989), Sep., 1811.

11) N. A. Fleck, Ø. Grong, G. R. Edwards and D. K. Matlock: Weld. J., May, (1986), 113s.

12) J. L. Lee: Acta Metall. Mater., 42 (1994), No. 10, $329 \mathrm{I}$

13) N. Christensen and T. Simonsen: Scand.J. Metall., 10 (198 I), 147. 